\title{
História e literatura no Brasil oitocentista: a historicidade do literário na crítica de José de Alencar a Gonçalves de Magalhães
}

\author{
History and literature in nineteenth-century Brazil: the historicity of the literary in \\ José de Alencar criticism to Gonçalves de Magalhães
}

\author{
Daniel Pinha Silva \\ Universidade do Estado do Rio de Janeiro \\ danielpinha@yahoo.com.br
}

\begin{abstract}
Resumo: Trata-se de uma análise das "Cartas sobre a Confederação dos Tamoios", série de artigos críticos escritos por José de Alencar em 1856 acerca do poema "A Confederação dos Tamoios", publicado por Gonçalves de Magalhães dois anos antes e aclamado por seus contemporâneos como texto fundador da literatura brasileira. Estes artigos apresentam uma maneira específica de Alencar considerar a historicidade do literário, questão cara aos princípios românticos em circulação no contexto letrado brasileiro oitocentista: de um lado, diálogo com uma forma literária universal capaz de atravessar os séculos, refazendo-se em contextos diversos; de outro, defesa da necessidade de contínua adequação entre forma literária e valores da época, associada, inclusive, a princípios que ultrapassam a dimensão literária - caso da experiência literária brasileira e o momento de formação da nacionalidade a partir das letras.
\end{abstract}

Palavras-chave: Romantismo brasileiro; José de Alencar; polêmicas literárias; modernidade literária; nacionalidade brasileira

\begin{abstract}
In 1856, Gonçalves de Magalhães published the poem "The Tamoios' Confederation ", acclaimed by his contemporaries as the founding text of Brazilian literature. Two years later, José de Alencar writes "Letters on the Tamoios' Confederation", a collection of critical articles on the poem which is the subject of this paper. The articles present Alencar's singular view of the historicity of the literary phenomenon, an issue identified with romantic principles within the Brazilian literate context of the nineteenth-century. On the one hand, Alencar dialogues with a universal literary form which crosses centuries and recreates itself in different contexts; on the other, he defends a compatibility between literary form and the values of the period, which reaches some principles beyond the literary dimension, as in the effect of the literary experience to the construction of the national identity in the nineteenth century.
\end{abstract}

Keywords: Brazilian Romanticism; José de Alencar; literary polemics; literary modernity; Brazilian nationality.

Artigo recebido para publicação em: setembro de 2014

Artigo aprovado para publicação em: novembro de 2014 
O leitor da Corte que abrisse o jornal O Globo em 10 de outubro de 1875 encontraria na coluna "Aos domingos" os seguintes dizeres a respeito do aclamado romancista José de Alencar:

Uma circunstância, porém, obriga-me a dizer tudo que penso do escritor, tantas vezes proclamado o chefe da literatura nacional, dignidade considerável sem dúvida, mas que parece indicar que para certas pessoas a nossa literatura é porquanto uma confraria.

Linhas abaixo complementava o articulista anônimo, em texto atribuído posteriormente ao ainda jovem Joaquim Nabuco:

\begin{abstract}
O Sr. Alencar, que revolta-se contra mim por não acreditar eu que nele Deus se tenha feito homem, não se recorda mais do modo por que aos seus vinte e sete anos, ainda pouco preparado, não tendo por si senão o seu estilo leve como oxigênio e quase imponderável, empreendeu ele a crítica da Confederação dos Tamoios e aluiu a reputação literária do Sr. Magalhães.

O Sr. Alencar acha mal o que escreve, no momento mesmo em que publica as suas cartas, mas não consente que nós sejamos de sua opinião vinte anos depois. ${ }^{2}$
\end{abstract}

Àquela altura, já era o quarto artigo que Nabuco dedicava à analise da obra literária escrita por José de Alencar. A série se iniciou após a publicação de um texto no qual Alencar fizera duras críticas ao público da Corte, que esvaziara a estreia de sua peça, O Jesuíta; o público era taxado por ele de eurocêntrico. Em seguida, no mesmo jornal, Joaquim Nabuco, que retornara de Paris há pouco, assinou um artigo em que lamentava a baixa qualidade do teatro brasileiro e, em consequência, a pobreza da peça de Alencar. Começava, assim, mais uma polêmica literária, tendo José de Alencar em um dos polos: aos domingos eram artigos de Nabuco revisando e comentando toda a obra literária de Alencar, enquanto às quintas Alencar respondia-lhe, defendendo o seu legado. Os textos da polêmica desenvolveram-se entre 3 de outubro e 21 de novembro daquele ano de 1875.

O trecho acima destaca o capítulo da vida literária de Alencar a respeito da "Polêmica sobre a Confederação dos Tamoios", ocorrida quase 20 anos antes. Tratava-se de um conjunto de oito cartas publicadas no Diário do Rio de Janeiro, entre 18 de junho e 15 de agosto de 1856, em que Alencar criticava negativamente o poema "A Confederação dos Tamoios", escrito pelo principal nome das letras brasileiras da época, Domingos José Gonçalves de Magalhães. Joaquim Nabuco compara o lugar que ocupava naquele momento da década de 70 com o lugar ocupado por Alencar em 1856, ou seja, o do jovem com "estilo leve e oxigênio quase imponderável" que atacava o principal nome da literatura de então para ressaltar a morte das suas ideias e o ultrapassado percurso percorrido por ele, enfatizando, ao mesmo tempo, a necessidade de se criar um novo caminho. Em outras palavras, ao considerar que a relação entre antigo e moderno consistia numa oposição que conduzia a uma superação, Nabuco compreendia que a concepção de modernidade literária defendida por Alencar contra Magalhães se esgotara, tornando-se ultrapassada com o decorrer do tempo. Deste modo, para Nabuco, o José de Alencar de 1875 ocupava o mesmo lugar do Gonçalves de Magalhães de 1856, ou seja, o lugar do cânon ultrapassado pelo novo. A vida literária de Alencar estaria pautada, então, por estas duas polêmicas, uma em que ele assumia a função de moderno e a outra, a de antigo, sinal de um nascimento e de um esgotamento. Assim, a

\footnotetext{
${ }^{1}$ NABUCO, Joaquim e ALENCAR, José de. A polêmica Alencar-Nabuco. Rio de Janeiro: Tempo Brasileiro, 1978, p. 67.

2 Idem, p. 72.
} 
modernidade literária proposta por Alencar estaria fadada a perder-se no fluxo da contínua renovação temporal.

Anos mais tarde, leremos em Silvio Romero concepção de modernidade semelhante, no livro em que se dedicou ao conjunto da obra de Machado de Assis.

O que Magalhães fez aos últimos representantes do classicismo praticou mais tarde Alencar com o próprio Magalhães; o que o autor do Guarani fez ao poeta da Confederação dos Tamoios recebeu, por sua vez, das mãos de Franklin Távora; as liberdades deste para com o romancista de Iracema pagou-as bem caro, levando, anos depois, formidáveis descomposturas de Mucio Teixeira, que por seu turno tem sido horrendamente maltratado por muitos dos chamados representantes dos novos ideais. E, sempre assim, um valentão das letras vai tomando outros. ${ }^{3}$

Ironicamente, o valentão da hora seria ele próprio, Silvio Romero, ocupado que estava em desvendar o verdadeiro caráter da literatura machadiana e revelar os anacronismos de Machado em meio às novidades propiciadas pela nova geração de 1870. Machado de Assis seria a prova viva do anacronismo, a representação máxima da sobrevivência de um tempo ultrapassado, que em nada teria contribuído para a formação da inteligência nacional: eis o cerne do argumento de Machado de Assis: estudo comparativo de literatura brasileira, livro de Silvio Romero publicado em 1897. Para o leitor da História da Literatura Brasileira, publicada em 1888, parece não haver novidade substancial na análise romeriana sobre Machado. A época e o meio natural sustentam e explicam a existência de autores e obras. Desse modo, é a nação brasileira que precisa se desenvolver a ponto de produzir em seu meio social um escritor da mais alta categoria literária - ao contrário de Machado, poupado por seus contemporâneos que, até então, não o teriam submetido a uma crítica correta. É a ausência de um passado, de uma tradição e de uma história que tornariam Machado apenas mais um brasileiro, ou seja, é a própria condição mestiça nas ideias que revela o que Romero chama de imprecisão literária, de um Machado que nunca desejou se integrar a um grupo ou a uma escola literária. De um modo ou de outro, observamos em Romero a recorrência da concepção de modernidade presente na crítica de Nabuco a Alencar.

Em estudo recente, Luiz Costa Lima apoia de certo modo a análise de Nabuco e Romero, qualificando este contínuo movimento de ideias do contexto letrado brasileiro - que tem nas polêmicas literárias seus momentos mais representativos - como sinal da incapacidade da cultura brasileira em produzir uma tradição. Em jogo estaria a automática sobreposição do passado pelo presente, característica de uma cultura baseada na constante afirmação de um marco zero.

Esta morte cultural de paternidade apresenta duas faces. Na primeira, regozijamo-
nos com nossa orfandade; não temos legado, herança ou tradição; ao começarmos,
a terra é outra vez virgem; marco zero, tudo em nós e de nós principia. A esta face
corresponde um incessante recomeço [...] As pedras lançadas contra as janelas
preparam os novos portais e estes justificam que os próximos jovens procurem ou
quebrá-los ou frequentar outras paragens. O círculo vicioso repete-se assim a cada
geração que surge. ${ }^{4}$

${ }^{3}$ Grifo Meu. ROMERO, Silvio. Machado de Assis: estudo comparativo de literatura brasileira. Campinas: Editora da Unicamp, 1992, p. 152.

${ }^{4}$ COSTA LIMA, Luiz. Dispersa Demanda: ensaios sobre literatura e teoria. Rio de Janeiro: Francisco Alves, $1981, \mathrm{p}$. 31. 
João Cezar de Castro Rocha, por sua vez, manterá a linha de argumentação de Costa Lima, ampliando-a em texto posterior. ${ }^{5}$ Para ele, Alencar cria essa "celeuma literária" motivado por uma preocupação pessoal, interessado em promover a ascensão de seu nome no círculo literário nacional. Desta maneira, o pesado juízo contrário ao "chefe das letras nacionais" colocava o então desconhecido articulista em condições de ser respeitado e admirado pela crítica e pelo público. Segundo Castro Rocha, entre os anos de 54 e 56, desde a publicação das primeiras crônicas de Ao correr da pena, o escritor já vinha imaginando diferentes maneiras de entrar no mundo das letras do Segundo Reinado. Assim, a polêmica seria "uma óbvia estratégia de inserção social" ${ }^{6}$ que forçava o seu ingresso no mundo das letras. Isso definiria uma forma específica de esvaziamento da esfera pública do debate letrado, em nome da consolidação de um circuito privado e restrito, uma cordialidade nas letras brasileiras que veio a se tornar o traço marcante da história da literatura brasileira oitocentista. Seria representativo, neste sentido, o episódio da polêmica sobre "A Confederação dos Tamoios" em que Alencar atua em nível público em prol de uma causa privada.

O presente texto persegue caminho diverso na análise das "Cartas sobre a Confederação dos Tamoios". A questão central a ser desenvolvida aqui não é a afirmação automática do novo na contínua superação do presente pelo passado; tampouco, a polêmica como estratégia de ressalte de prestígio ante o circuito literário da Corte. As "Cartas" revelam, sobretudo, o destaque dado por Alencar para o problema da forma literária que, segundo ele, deve estar adequada a critérios locais e epocais, sem, contudo, abrir mão de uma tradição acumulada pelo passado literário, a qual o presente deve mobilizar. Ou seja, embora atrelado ao instinto de nacionalidade disseminado pelas letras brasileiras nos oitocentos, ${ }^{7}$ Alencar problematiza nas "Cartas" a historicidade das formas literárias, trazendo para primeiro plano um princípio romântico adequado ao contexto letrado brasileiro. A passagem abaixo sintetiza esta proposta:

Escreveríamos um poema, mas não um poema épico; um verdadeiro poema nacional, onde tudo fosse novo, desde o pensamento até a forma, desde a imagem até o verso.

A forma com que Homero cantou os gregos não serve para cantar os índios; o verso que disse as desgraças de Troia, e os combates mitológicos não podem exprimir as tristes endechas do Guanabara, e as tradições selvagens da América.

Por ventura não haverá no caos incriado do pensamento humano uma nova forma de poesia, um novo metro de verso? ${ }^{8}$

De modo geral, as "Cartas" de Alencar desenvolvem-se em torno de dois descompassos encontrados na composição de Magalhães. O primeiro refere-se a uma possível inadequação da forma epopeia como gênero literário apropriado para cantar a natureza e os costumes propriamente brasileiros; o segundo destaca uma incoerência de "A Confederação dos Tamoios" com o próprio gênero epopeia a que se dispõe a escrever. Partindo destas discordâncias, Alencar coloca a forma literária nacional como problema a ser resolvido por sua época, assegurando que a literatura brasileira encontrava-se em processo

\footnotetext{
${ }^{5}$ ROCHA, João Cezar de Castro. Literatura e Cordialidade: o público e o privado na cultura brasileira. Rio de Janeiro: Eduerj, 1998.

6 Idem, p. 41.

${ }^{7}$ Machado de Assis, em 1873, explicitou o sentido desse instinto de nacionalidade no texto "Notícia atual da literatura brasileira: instinto de nacionalidade". Nas palavras de Machado: "Quem examina a atual literatura brasileira reconhece-Ihe logo, como primeiro traço, certo instinto de nacionalidade. Poesia, romance, todas as formas literárias do pensamento buscam vestir-se com as cores do país, e não há negar que semelhante preocupação é sintoma de vitalidade e abono do futuro". ASSIS, J. M. Machado de. Obra completa. Rio de Janeiro: Ed. Nova Aguilar, 1962, v. III, p. 801.

8 ALENCAR, José de. "Cartas sobre a Confederação dos Tamoios" In: ALENCAR, José de. Obra Completa. Rio de Janeiro: Editora José Aguilar, 1960, vol. IV, p. 876.
} 
inacabado de formação. É neste sentido que o autor deixa em aberto a indagação: "haverá no caos incriado do pensamento humano uma nova forma de poesia, um novo metro de verso?".

\section{O Romantismo e o caso brasileiro: nação, literatura e história}

O Romantismo, em que pesem suas especificidades nacionais, possui, de acordo com Stephen Bann, um desejo de história como linha que atravessa todo o movimento. Este desejo não se circunscreve apenas à formação do campo disciplinar história, com uma determinada padronização de seus métodos, mas também se estende a outros campos culturais, como a arquitetura, o romance e a pintura histórica, sendo consumido por um público cada vez maior na Europa. Além disso, o autor pondera que o Romantismo expande-se para além dos limites daquele continente, levando, para onde vai, o tal "desejo de história". Nas palavras de Bann, "a consciência histórica é produto de um período romântico, quando o passado se torna possível de representação". ${ }^{9}$

Para o autor, a partir da referência da história há a formação de uma nova linguagem em que o passado oferece base para as mais diversas atividades culturais: "Se a ciência abomina o continuum, a história abomina a descontinuidade". ${ }^{10}$ Abominar uma descontinuidade significa elevar a primeiro plano a busca pela definição das heranças às quais pertencem os homens do presente - cabendo a estes produzir as tradições em que querem se inserir - como herdeiros legítimos. Conferir um sentido a esse passado e "enformá-lo" em história significa localizar no passado o início desse processo e apontar para o futuro sua completa realização. Ao mesmo tempo, legitima-se um presente em construção pelo sentido que é dado às experiências humanas no passado, atrelando-o muitas vezes a demandas políticas deste presente - caso dos projetos de afirmação dos Estados nacionais, por exemplo.

Em uma época marcada pela valorização do particular, forjado em nacional, como elemento diferenciador das literaturas, o caso brasileiro tem como traço específico as intensas relações entre a independência política e a literária, levando em conta a declaração de independência política em 1822 . Na apreciação de Antônio Candido, ${ }^{11}$ a autonomia política foi importante para a elaboração das ideias românticas por três motivos: com ela, ressaltou-se o desejo de exprimir uma nova ordem de sentimentos pautados em um orgulho patriótico, apresentado como continuidade da ideia de nativismo; como desdobramento, uma vontade de criar uma literatura independente, não apenas uma literatura, colocando o problema do nacionalismo literário e a busca de novos modelos; por criar a noção de que a atividade letrada deve servir a uma tarefa patriótica na construção do brasileiro, ainda em nascimento.

Nesse sentido, a novidade do Brasil atrelava-se profundamente à novidade literária do Romantismo, que servia tanto como fator de diferenciação do nacional quanto como espaço para inserir o país em pé de igualdade com outras nações do Ocidente. Este é um argumento que Abel Barros Baptista desenvolve:

A proposta de nacionalização literária que afastasse e distinguisse uma literatura verdadeiramente brasileira da europeia e, em particular, da portuguesa, é europeia na sua origem e seu sentido, por ser antes do mais de natureza literária, solidária de uma concepção de literatura e de uma atitude perante a tradição que começam a fazer sentido no quadro das tradições da época. ${ }^{12}$

\footnotetext{
9 BANN. Romanticism and rise of History. New York: Twaine Publishers, 1995, p. 6.

${ }^{10}$ Idem, p. 7.

${ }^{11}$ CANDIDO, Antônio. Formação da literatura brasileira: momentos decisivos. Belo horizonte, MG: Editora Itatiaia, 2000, vol. II.

12 BAPTISTA, Abel Barros. A formação do nome: duas interrogações sobre Machado de Assis. Campinas, São Paulo: Editora da Unicamp, 2003, p. 25.
} 
O autor salienta que quanto mais a busca pela especificidade do nacional toma conta dos debates acerca da literatura brasileira tanto mais ela se filia ao projeto romântico, que teve uma origem e um sentido fundados no Velho Continente. $O$ autor acrescenta ainda que, com o Romantismo, inaugura-se uma nova maneira de conceber a tradição e esta nova atitude estará presente entre brasileiros e europeus: uma atitude moderna que sublinha principalmente a individualidade da própria época em relação ao tempo histórico. Nas palavras de Baptista:

O que é fundamental reconhecer é que nele [no Romantismo] encontramos um impulso que ainda se deixa situar no domínio do especificamente literário: a orientação para o presente, a procura de uma realidade exterior à literatura capaz de sustentar a recusa do passado e satisfazer a paixão do novo e do começo radical. Numa palavra: o impulso de modernidade.

Os românticos brasileiros viveram-no na ilusão de um duplo começo: começo do Brasil enquanto nação independente, começo da literatura brasileira enquanto literatura verdadeiramente nacional. [...]

O problema está em que, no quadro do projeto nacional inaugurado pelo romantismo, a originalidade, a novidade e a diferença da literatura brasileira se estendem fundadas na originalidade, na novidade e na diferença do próprio Brasil: será possível, então, acreditar que o Brasil não resiste à literatura e que esta, por sua vez, não resiste ao Brasil. $^{13}$

A ênfase na dimensão particular própria às sensibilidades românticas, e que dará fundamentação a várias experiências nacionais ao longo do século XIX, terá na apreensão historicizante da literatura um aliado fundamental. A afirmação de bases românticas fundadas em uma estética historicista no campo literário teria surgido no final do século anterior. Luiz Costa Lima ${ }^{14}$ identifica o debate alemão do último quarto do século XVIII como o propulsor do questionamento do ideal clássico fundado nas ideias de unidade, peremptoriedade das classificações formais e retóricas e tradição atemporal, tida como ideal a ser perseguido. ${ }^{15}$ Tal ideal clássico e universal teria sido ativado pela razão iluminista setecentista, em sua incessante busca por leis universais e atemporais que pudessem explicar fenômenos naturais, físicos ou morais. ${ }^{16}$ O Romantismo oferece à arte, em contrapartida, uma nova legitimação, pautada agora na explosão do sujeito individual - materializada na figura do gênio - e na ascensão do discurso histórico como forma de compreender novas unidades fundadoras de sentido, adequadas ao suposto de que "cada época possui seu centro de gravidade". ${ }^{17}$ A rigidez clássica não consegue mais expressar as novas necessidades

${ }^{13}$ Idem, pp. 28-9. Grifo meu.

${ }^{14}$ COSTA LIMA, Luiz. O controle do imaginário: razão e imaginação nos Tempos Modernos. Rio de Janeiro: Forense Universitária, 1989.

${ }^{15}$ De acordo com Hans R. Jauss a contestação a esse ideal de literatura fundado na tradição teria aparecido pela primeira vez com a "Querela antigos e modernos" da Academia de Literatura Francesa do século XVII. In JAUSS, Hans R. "Tradição literária e consciência atual da modernidade". In: OLINTO, Heindrun Krieger. Histórias de Literatura. As novas teorias alemãs. São Paulo: Ática, 1997. No entanto, o fundamento das sensibilidades românticas no quadro europeu encontra-se vinculado ao debate alemão do último quarto do século XVIII, como demonstra Costa Lima, cuja liderança coube a Friedrich Schlegel (1772-1829). A esse respeito ver SUZUKI, Marcio. O Gênio Romântico: Crítica e História da Filosofia em Friedrich Schlegel. São Paulo: Iluminuras/ Fapesp, 1998.

${ }^{16}$ COSTA LIMA, L. Op. cit. pp. 73-4.

${ }^{17}$ Esse é suposto da crítica historicista de Johann Gottfried Herder (1744-1803) ao lluminismo francês. Para Herder, o lluminismo instaura no pensamento o monopólio da razão, esta mesma considerada por ele como própria de um tempo histórico. Assim, as luzes submetiam todas as épocas à lógica causal do próprio tempo, privando assim o filósofo de perceber a complexidade do gênero humano na diversidade dos tempos anteriores. Para compreender o espírito do tempo, segundo Herder, há de se fazer um esforço de descentramento, ou seja, sair do próprio centro, de modo a perceber a diferença entre tempos e o alcance do maravilhamento, em busca da natureza interna do espírito da sociedade. Nas palavras de Herder: "Como cheios de certezas somos levados a fantasiar pelo espírito e pela sensibilidade do nosso tempo. Configurava-se uma submissão respeitosa ao mínimo sinal superior [...] Mas será que não vemos que o espírito daquele tempo, daquele lugar, daquele estádio do gênero humano, tudo era completamente diferente? [...] O homem começa por se espantar com todas as coisas para só depois, de fato, vê-las. Só por meio do maravilhamento chega depois a ideia do clarificada, do verdadeiro e do belo". In: HERDER, Johann Gottfried. 
do século e do espaço e a literatura passa a expressar diferentes dimensões da vida humana. Nas palavras de Costa Lima:

Assim, ao passo que a estética neoclássica professava, junto com o iluminismo mais popularizado, a crença em valores trans-históricos - as normas a que as obras deviam se sujeitar e a razão, respectivamente - o historicismo estético concedia maior realce aos elementos contextuais, como o clima, a educação, as viagens e, sobretudo, a língua. ${ }^{18}$

O que qualifica primordialmente essa forma de conceber a literatura é um completo atrelamento existente entre ela e as circunstâncias seculares que a compunham, daí a primazia dos chamados elementos contextuais, citados por Costa Lima. Ao longo do século XIX estes elementos estarão associados ao surgimento das nações modernas, incitados pela obra da Revolução Francesa. A literatura nos oitocentos tornar-se-ia, dessa maneira, filha não apenas de seu tempo e do gênio que a gerou, mas de sua nação.

\section{Em defesa de Magalhães: a literatura como fato moral}

Líder de um grupo, Gonçalves Magalhães parece ter assumido sem hesitar a tarefa de precursor de um movimento de ideias no Brasil. Fundador da Niterói e colaborador assíduo dos volumes da revista, Gonçalves de Magalhães consegue marcar uma presença constante na Minerva, mesmo assinando poucos artigos. Segundo Roque Spencer Maciel de Barros, de novembro de 1843 a junho de 1845 - período de circulação da revista - tal colaboração se resumiu a uma "Ode" oferecida ao Duque de Caxias em menção à paz obtida na província do Rio Grande do Sul, a um pequeno artigo dedicado à origem da palavra, e a uma noveleta, intitulada "Amâncio". Esta presença se justifica, segundo Barros, principalmente porque Magalhães, mesmo ausente da Corte em missão diplomática na França, é autor deveras mencionado em textos da revista, consolidando-se como um importante canal de diálogo de escritores da Minerva:

\footnotetext{
Ausente da corte, ele continua olhado como a figura máxima da nossa literatura, como o renovador, o chefe, aquele que nos abriu o caminho romântico, com tudo que este caminho envolve em matéria de consciência nacional e de busca de um futuro próprio, original e esperançoso. ${ }^{19}$
}

O prefácio à primeira edição do seu livro de poesias, Suspiros poéticos e Saudades, publicado em 1836, intitulado "Lede", indica essa reivindicação de protagonismo. Magalhães imprime neste texto um tom de manifesto, enaltecendo a importância da genialidade romântica. A individualidade criadora seria a principal responsável pela maneira como ele dispunha seus pensamentos: a bela elaboração literária dependia do acento à inspiração. Na linha de raciocínio de Magalhães, a produção do novo dar-se-ia por um rompimento com a tradição clássica que, segundo ele, aprisionaria o pensamento a formas constituídas a priori. Em outras palavras, tradição formal clássica e inspiração poética caminhariam por vias opostas:

Também uma filosofia da história para a formação da humanidade: uma contribuição a muitas contribuições do século. Lisboa: Edições Antígona, 1995, p. 15.

${ }^{18}$ COSTA LIMA, L. Op. cit. p. 117.

${ }^{19}$ BARROS, Roque Spencer Maciel de. A significação educativa do romantismo brasileiro: Gonçalves de Magalhães. São Paulo: Ed. da Universidade de São Paulo: Grijalbo, 1973, p. 124. 
Quanto à forma, isto é, a construção, por assim dizer, material das estrofes, e de cada cântico em particular, nenhuma ordem seguimos exprimindo as ideias como elas se apresentaram, para não destruir o acento à inspiração; além de que, a igualdade dos versos, a regularidade das rimas, e a simetria das estâncias produzem tal monotonia, e dão certa feição de concertado artifício que jamais podem agradar. $^{20}$

Para Magalhães, o acento à inspiração estaria prejudicado caso fosse submetido a uma construção formal rígida e estática. A particularidade e a inspiração de cada cântico levaria à constituição de uma forma específica, que se conformaria ao mesmo tempo em que o poema fosse escrito. Neste sentido, o gênio era dotado de capacidade para romper fosse com a chamada "monótona regularidade de rimas" ou com qualquer outra regra métrica, deslocando para a própria pena o traço de beleza poética.

A centralidade de Gonçalves de Magalhães no primeiro grupo romântico brasileiro é exposta de maneira clara quando analisamos, por exemplo, o modo como ele foi defendido por Manoel de Araújo PortoAlegre e por artigos atribuídos a D. Pedro II, nas respostas que eles deram às "Cartas" de José de Alencar. Estes textos, publicados após a quinta carta de Alencar, revelam o quanto as críticas do futuro romancista atingiam não apenas Magalhães, mas todo o grupo que tinha nele o representante mais notório. Revelavam também as características literárias defendidas por esse grupo. ${ }^{21}$

Data de 23 de julho de 1856 a publicação do primeiro artigo de Manoel de Araújo Porto-Alegre, assinado com o pseudônimo "o amigo do poeta", nas páginas do jornal Correio da Tarde. Nos trechos abaixo lemos o argumento principal do autor: "Um livro, como o poema nacional de que tratamos, não é um deleite métrico, um romance em verso; mas sim um fato moral que pode ser avaliado de outra maneira, e que exige uma análise considerada". ${ }^{22}$ Complementando ainda, mais adiante:

O grande princípio, o pensamento edificador que preside ao todo d'esta obra nacional, não pode ser avaliado por homens cujo coração está vazio; e a quem não importa o futuro daquela grande entidade denominada PÁTRIA, enquanto podem viver nos gozos materiais, e refocilar-se nas frioleiras de uma nunca e interrompida infância. Mas felizmente houve quem compreendesse a missão do poeta; quem fortificasse o seu nobre empenho e lhe prestasse a mais decidida proteção. ${ }^{23}$

O fato moral está acima de qualquer crítica sobre peculiaridades formais do poema, estas vistas como secundárias. Deste modo, a ênfase se direciona a algo que precede à escrita do poema, algo essencial que perpassa as mais diferentes expressões artísticas: o instinto de Pátria, ou ainda, o futuro desta entidade. Para Porto-Alegre, é inquestionável a relevância do episódio histórico da confederação dos Tamoios, pela relevância que possui nos destinos da história brasileira. Cantado em suas minúcias pelos versos de um Gonçalves de Magalhães, um acontecimento como aquele só poderia ser criticado por um autor incapaz de apreciar devidamente a cor local, o passado e o futuro do país.

20 MAGALHÃES, Domingos José Gonçalves de. "Lede". In: COUTINHO, Afrânio (org.). Caminhos do pensamento crítico. Rio de Janeiro, Pallas; Brasília INL, 1980, Vol. I., p. 40. Grifo meu.

${ }^{21}$ Este argumento já foi defendido primeiramente por José Aderaldo Castello. Nas palavras do autor: "Cremos que as cartas de Porto-Alegre, tentando inicialmente responder às críticas de Alencar e de modo geral pretendendo a valorização de Gonçalves de Magalhães, têm o valor de documentar o espírito da geração ou do grupo a que se filiou o escritor, espírito dominado, entre outras coisas, pelo arrebatamento nacionalista e pela preocupação de exaltar as figuras que o integravam". CASTELLO, Jose Aderaldo. A Polêmica sobre a confederação dos Tamoios e o indianismo romântico. São Paulo: Faculdade de Filosofia, Ciências e Letras da Universidade de São Paulo, 1953, p. $\mathrm{X}$.

${ }_{22}$ PORTO-ALEGRE, Manuel de Araújo. "O amigo do poeta”. In: CASTELLO, José Aderaldo (org.). Op. cit. p. 65.

${ }^{23}$ Idem, p. 69. Grifo meu. 
No artigo de 28 de julho, Porto-Alegre avança ainda mais neste ponto. Ele critica os exemplos da arte moderna, qualificando como triunfo do detalhe a ênfase que artistas modernos conferiam a determinados assuntos. O autor das "Cartas sobre a Confederação dos Tamoios" pecaria pelo mesmo problema, perdendo o enfoque "do assunto principal pela prodigiosa beleza dos detalhes": ${ }^{24}$ "Os dogmas da moral e da nacionalidade permanecem a par das grandes proporções daquele todo artístico, e acompanham o desenvolvimento da ação nesse antagonismo progressivo entre o homem selvagem e o civilizado" ${ }^{25}$

Propondo adiante que: "Um poema pode ser um primor de um grande fato moral, um exemplo edificante, sem longas descrições eróticas, sem uma mulher formosa, e sem que a lua venha alumiar as cenas de seus painéis". 26

Neste trecho, o amigo do poeta responde diretamente a Alencar sobre as insinuações do crítico em relação à pobreza da personagem feminina ${ }^{27}$ e das descrições dos cenários do poema. $O$ ponto que merece destaque, no entanto, é uma vez mais o fato moral: é em nome dele que o poema deve existir. Graças a ele, Magalhães consolida-se como um legítimo patriota que, nas palavras de Porto-Alegre, "por amor de uma ideia nacional deixará à margem esse lirismo erótico, que muito pouco se compadece com o painel de sua concepção", ${ }^{28}$ justificando assim a magnitude do poema.

Para João Cezar de Castro Rocha, no entender de Araújo Porto-Alegre, José de Alencar cometera um erro duplo em sua leitura do poema de Gonçalves de Magalhães: de um lado, lê "A Confederação dos Tamoios" como apenas mais um poema, um poema secular, desconsiderando completamente a posição ocupada pelo poeta; e, por outro, deixa de lado a relevância da obra e de Magalhães na formação da nacionalidade brasileira, desconsiderando a principal propriedade do poema, que seria, nas palavras de Castro Rocha: "Um fato moral. Um factum que, com a força imanente do destino, não pode ser contrariado". ${ }^{29}$ Ao desafiar Magalhães, Alencar não apenas admite a crítica como uma tarefa secular, mas também desautoriza o argumento de autoridade em torno de um nome.

\section{Alencar e a defesa da historicidade da forma literária}

O argumento central de José de Alencar nas "Cartas sobre a Confederação dos Tamoios" é o de que a poesia não está à altura do assunto, ou ainda, há um descompasso entre aquilo que se apresenta como forma poética e o assunto que é tratado. Já nas primeiras linhas da "Carta Primeira", de 18 de junho, Alencar apresenta a questão: "Depois da invocação [ao sol] segue a descrição do Brasil: há nessa descrição muitas belezas de pensamento, mas a poesia não está à altura do assunto". ${ }^{30}$

${ }^{24}$ Idem, p. 74.

25 Idem, p. 71.

${ }^{26}$ Idem, p. 72. Grifo meu.

${ }^{27}$ Sobre a precariedade da personagem feminina no poema de Gonçalves de Magalhães, assinala Alencar: "todos os poetas e todos os artistas que inspiraram o seu gênio nesse assunto divino da mulher se esforçaram por criar alguma coisa. [...] Como Milton, como Ossian, como Chateaubriand, o Sr. Magalhães, escrevendo um poema nacional, estava obrigado a formar de sua heroína uma mulher que pudesse figurar a par dessas imagens graciosas que a literatura conserva. [...]. Entretanto a heroína do poema do Sr. Magalhães é uma mulher como qualquer outra; as virgens índias de seus livros podem sair dele e figurar em um romance árabe, chinês ou europeu; se deixassem as penas do tucano que mal as cobrem, podiam vestir-se à moda em casa de Mme Barat e Gudin, e ir dançar a valsa no Cassino e no Clube com algum deputado". ALENCAR, Jose de. "Cartas sobre a Confederação dos Tamoios". In:

Obra Completa. Rio de Janeiro: José Aguilar, 1960, v. IV, p. 878.

${ }^{28}$ Idem. p. 74.

${ }^{29}$ ROCHA, João Cezar de Castro. Op. cit. p. 47.

${ }^{30}$ ALENCAR, J. de. Op. cit.p. 864. 
O desajuste poesia/ assunto se revela inteiramente no momento em que Gonçalves de Magalhães se refere à vida e à tradição dos índios. Para Alencar, o problema maior a ser combatido na literatura brasileira não era a ênfase em assuntos indígenas - que marcavam a corrente indianista - mas o fato de um poeta não conseguir converter tais assuntos em poesia, como teria ocorrido com Magalhães. A falta de poeticidade, segundo Alencar, tornava "A Confederação dos Tamoios" não mais do que uma cópia sem beleza dos cronistas coloniais, mero encadeamento de palavras indígenas que, por falta de uma forma adequada, não conformavam uma poesia nacional. Ou seja, Alencar defende a preservação de um princípio literário comum capaz de atravessar as épocas, princípio este que a novidade brasileira não deve recusar, mas sim assimilar. No trecho abaixo, retirado da "Quarta carta", de 5 de julho de 1856, este ponto se evidencia:

\begin{abstract}
De algum tempo se tem manifestado certa tendência de reação contra essa poesia inçada de termos indígenas, essa escola que pensa que a nacionalidade da literatura está em algumas palavras: a reação é justa, eu também a partilho, porque entendo que esta escola faz grande mal ao desenvolvimento do nosso bom gosto literário e artístico.

Mas o que não partilho, e o que acho fatal, é que essa reação se exceda; que em vez de condenar o abuso, combata a coisa em si; que em lugar de estigmatizar alguns poetastros que perdem o seu tempo a estudar o dicionário indígena, procure lançar o ridículo e a zombaria sobre a verdadeira literatura nacional. ${ }^{31}$
\end{abstract}

$\mathrm{Na}$ "Carta Segunda" de 22 de junho, ao ressaltar as qualidades literárias do francês René Chateaubriand, a defesa desse princípio torna-se ainda mais evidente. Há também o destaque para a genialidade autoral e a inspiração da natureza - tópicos recorrentes em textos românticos. A mera descrição das maravilhas naturais não parece ser suficiente para assegurar a beleza poética de um texto literário.

O Brasil, o filho do sol, com todo o seu brilho e luxo oriental, com toda sua esplêndida beleza, cede a palma à América do Norte: o Ohio e o Mississippi vencem o Amazonas e o Paraná; as regiões setentrionais ofuscam os raios do meridiano!

É verdade que elas tiveram a pena de Chateaubriand para descrevê-las, e a alma de um grande poeta para sentir e compreender o que havia nelas de grande e sublime. $^{32}$

Este argumento é aprofundado quando o articulista defende, na "Quarta Carta", que todo e qualquer assunto é passível de poesia, desde que haja uma pena que a justifique enquanto tal. Assim, o escritor chega a fazer referência a exemplos de temas literários considerados esdrúxulos:

Chateaubriand n'O Gênio do Cristianismo achou uma fonte inesgotável descrevendo a delicadeza do sentimento da maternidade no jacaré, em um réptil monstruoso e disforme; Virgílio escreveu um poema sobre um mosquito, e Buffon na sua história natural é um poeta que faz um poema sobre cada animal, cada ser da criação, ainda mesmo aqueles que nos parecem os mais desprezíveis. ${ }^{33}$

E adiante, ele complementa:

Em tudo, pois, há poesia, contanto que se saiba vibrar as cordas do coração, e fazer cintilar esses raios de luz que Deus deixou impresso em todas as coisas como o

\footnotetext{
${ }^{31}$ Idem. p. 885.

${ }^{32}$ Idem. p 869.

${ }^{33}$ Idem. p. 886. 
cunho de seu poder criador; em tudo há o belo, que é senão o reflexo da divindade sobre a matéria. ${ }^{34}$

Além de uma forma literária capaz de atravessar os séculos, Alencar apresenta a criação poética como resultado da presença divina na inspiração humana. Em todas as coisas da natureza há um raio de luz, cabe ao poeta conseguir desvendá-lo; há uma unidade transcendente presente em Deus, a qual o poeta tenta alcançar, ainda que essa tarefa contenha sempre uma frustração. Se a natureza é resultado maior da criação divina, o homem Dele se aproxima quando transforma a beleza da natureza em beleza poética. Para Alencar, esta transformação opera-se, de um lado, como dom divino, e de outro, como atributo humano, já que ele leva em consideração a capacidade do poeta em transformar um assunto qualquer em literatura, o que significaria fazer uso apropriado de uma tradição literária na qual a sua poesia se insere. Em outras palavras, a realização do ideal poético depende, além do dom, de um domínio secular de atributos literários que transformem o simples texto em literatura. Este pleno domínio significa a adequação da produção literária a uma forma que esteja designada por uma tradição literária, tradição esta que deve estar sempre à disposição de uma readaptação aos diferentes tempos presentes.

É fundamental para Alencar, neste sentido, não apenas equilíbrio, adequação ou equiparação do assunto à poesia, mas que haja também uma adequação do texto ao gênero literário que ele se propõe a caracterizar. A proposta romântica de Alencar não sugere a explosão dos gêneros em nome de uma maior liberdade poética do gênio - como deixa transparecer Magalhães no prefácio "Lede" dos seus Suspiros poéticos e Saudades. ${ }^{35}$ Ao contrário, ele sugere uma acuidade extrema do escritor em relação ao devido uso do gênero literário de que ele lança mão. É nesse sentido que Alencar enfatiza a inadequação entre "A Confederação dos Tamoios" e o gênero epopeia. Este assunto é mencionado pelo autor desde a "Primeira Carta": "A Confederação dos Tamoios começa por um episódio: é a morte de um simples guerreiro índio, assassinado por dois colonos, que decide da aliança das tribos indígenas contra a colônia de São Vicente" ${ }^{36}$ Complementando adiante:

Devemos confessar que a causa do poema, o princípio da ação não está de modo algum nas regras da epopeia. Derivar de um fato acidental e sem importância a luta de duas raças, a extinção de um povo e a conquista de um país é impróprio da grandeza do assunto. ${ }^{37}$

Para ele, o poeta épico deve sempre elevar a grandeza e a majestade de seus heróis, conferindo muitas vezes uma origem divina ou heroica aos povos que pretende cantar. A poesia de Magalhães não alcança este objetivo, pois o episódio inicial é demasiado simples para justificar a importância do restante da história - no primeiro canto, a personagem principal da história, o índio Aimbire, lamenta a perda de um amigo de infância em batalha contra portugueses e resolve vingar a morte do companheiro, unindo a tribo dos Tamoios em torno de uma Confederação contra os colonizadores. $O$ evento que origina o percurso heroico do povo Tamoio é motivado por uma causa pessoal, insuficiente para causar uma guerra que levasse à libertação daqueles indígenas.

\footnotetext{
${ }^{34}$ Idem. p. 886.

${ }^{35}$ Refiro-me à seguinte passagem: "Quanto à forma, isto é, a construção, por assim dizer, material das estrofes, e de cada cântico em particular, nenhuma ordem seguimos [não segue nenhuma ordem em específico] exprimindo as ideias como elas se apresentaram, para não destruir o acento à inspiração; além de que, a igualdade dos versos, a regularidade das rimas, e a simetria das estâncias produzem tal monotonia, e dão certa feição de concertado artifício que jamais podem agradar". MAGALHÃES, Gonçalves de. Op. cit. p. 40.

${ }^{36}$ Idem. p. 866.

${ }^{37}$ Idem. 867.
} 
O destaque dado por Alencar à desobediência do poema de Magalhães a respeito das exigências internas do gênero épico, entretanto, não o faz fixar a epopeia em um padrão uniformizador imune à dinamicidade do tempo histórico. Isto é o que ele aponta na "Oitava Carta", que encerra o conjunto de artigos:

Todas elas foram escritas em circunstâncias diferentes; umas são mitos ou ideias poetizadas que preludiam o nascimento de uma nova religião, de uma nova civilização, de uma nova língua ou mesmo de uma nova literatura; neste número estão a Bíblia, a llíada, a Divina Comédia, os Nibelungen e os dramas de Shakespeare. $^{38}$

Como todos os gêneros literários, as epopeias carregam em si a época em que foram elaboradas. Em diferentes presentes elas podem representar o nascimento de algo novo, considerando a especificidade do momento histórico. Isto não seria diferente no caso brasileiro oitocentista, quando os contornos nacionais apareciam no mundo letrado - conforme vimos linhas acima - em busca de marcos definidores da origem do país no passado, ainda que houvesse o reconhecimento da novidade do Brasil como nação nos quadros de uma cultura ocidental mais ampla.

Tanto a defesa da adequação do texto ao seu devido gênero literário quanto a afirmação de uma forma literária capaz de atravessar os séculos - a partir da qual, cada presente deve se apropriar seletivamente - nos revelam que o estatuto de modernidade defendido por José de Alencar nas "Cartas sobre a Confederação dos Tamoios" não equivale ao paradigma de modernidade que impõe a superação automática do passado pelo presente - como afirmaram Joaquim Nabuco e Silvio Romero no século XIX e, mais recentemente, Luiz Costa Lima e João Cezar de Castro Rocha. O que está em jogo, em José de Alencar, é a defesa de um procedimento seletivo de apropriação do passado pelo presente, capaz de considerar o acúmulo de experiências literárias passadas, preservadas no presente enquanto tradição. Tal procedimento preserva um ideal de literatura, que remete a uma dimensão histórica mais ampla e universal, adequando-a ao contexto brasileiro do presente oitocentista, reconhecido por Alencar como momento de formação da literatura brasileira.

O oitavo e último artigo escrito por José de Alencar sobre "A Confederação dos Tamoios" de Gonçalves de Magalhães é publicado em O Diário do Rio de Janeiro em 15 de agosto de 1856. A essa altura, a polêmica travada entre Alencar e os amigos do poeta chegava às últimas linhas. O leitor que acompanhou a sequência das cartas pôde perceber uma significativa diferença no tom das críticas de Alencar ao longo daqueles dois meses. Se nas cinco primeiras cartas, quando nenhum dos defensores de Magalhães ainda havia se manifestado, a pena do autor era mais amena com passagens que reconheciam, inclusive, virtudes do poema, após a entrada em cena de Manoel de Araújo Porto-Alegre, D. Pedro II, Frei Francisco de Monte Alverne, entre outros, Alencar assumiu uma postura mais severa em relação ao poema. O próprio autor reconhecia ser mais incisivo no momento em que seus textos passaram a ter interlocução. Em suas palavras:

$\mathrm{Na}$ primeira série de minhas cartas fui menos severo, porque dirigia-me ao poeta ausente; desde porém que apareceu um amigo e defensor tão ilustrado e tão distinto, como o escritor das Reflexões, entendi que podia ser franco, sem incorrer na pecha de desleal. ${ }^{39}$

\footnotetext{
38 Idem. p. 911.

${ }^{39}$ Idem. p. 914. 
Mais radical ou menos, há em Alencar a defesa da polêmica literária como espaço ideal para a afirmação de um espaço público de debate letrado, fomentado pelo desenvolvimento da crítica e de um público leitor. O enfraquecimento do debate conduz à esterilidade, daí certa sensação de frustração que ele expressa na sua "Última carta", em 14 de julho: ${ }^{40}$

Sofri uma decepção, a imprensa calou-se, os literatos limitaram-se a dizer a sua opinião nos seus diversos círculos; e apenas depois de muitos dias apareceu em um jornal uma espécie de diatribe, que devo esquecer, meu amigo, por honra de nosso país e de nossa classe. [...] Em vez de aceitar-se uma discussão literária, franca e leal, se procurava uma luta mesquinha e baixa. ${ }^{41}$

José de Alencar assumiu um caráter polemista em toda a sua vida letrada. Ao longo dos cerca de 20 anos em que se empenhou na tarefa de escritor, o romancista envolveu-se em diversas polêmicas como a já citada aqui, com Joaquim Nabuco - mesmo quando já era uma referência para o romantismo brasileiro e um dos romancistas mais lidos do Império. A polêmica literária era uma opção de Alencar para assegurar uma forma específica de usar sua pena como arma, como modo de conhecer e guerrear - nos termos de Antônio Edmilson Martins Rodrigues. ${ }^{42}$

$\mathrm{Na}$ oitava e última carta, Alencar explicita o que seria a maior motivação da escrita de todos aqueles artigos:

O papel do crítico tem sempre um laivo de odiosidade; mas espero que quem me conhecer, e que não fui levado nem por despeito e sim pelo desejo de que a imprensa assinalasse, mais do que uma simples notícia, o aparecimento de uma obra nacional; julgará de minha opinião sem envolver nela os sentimentos do homem. ${ }^{43}$

Seguindo, mais adiante:

Tendo concluído as minhas cartas, embora não merecessem elas as honras de uma refutação, julguei que, ao menos em atenção ao poema, dessem causa a uma dessas polêmicas literárias, que têm sempre a vantagem de estimular os espíritos alguma coisa de novo e de bom. $^{44}$

A publicação de um poema celebrado com o status de epopeia fundadora da nacionalidade brasileira não podia ser aceita como notícia fortuita e superficial. "A Confederação dos Tamoios" não podia ser recebida simplesmente como uma evidência, com a aceitação passiva de quem o lesse; ao contrário, o poema era não apenas passível de crítica - deixando de lado, assim, a compreensão de que se tratava de um fato moral que suplantava quaisquer questões de ordem estética - como a crítica era, em si, fundamental para o fomento de uma "República das Letras", essencial para uma literatura brasileira em formação. À crítica caberia empreender não apenas a defesa das virtudes do gênio literário romântico em sua liberdade criativa - de acordo com os critérios românticos - mas também a defesa de que o escritor

\footnotetext{
${ }^{40}$ Após essa carta, Alencar publicou outras três, portanto, esta "Última carta" viria a tornar-se o quinto artigo da série.

${ }^{41}$ Idem. p. 896-7.

${ }^{42}$ Nas palavras de Antônio Edmilson Rodrigues: "Alencar transformou-se com o tempo num poeta armado que usou a letra como modo de conhecer e guerrear". RODRIGUES, Antônio Edmilson Martins José de Alencar: O poeta armado do século XIX. Rio de Janeiro: Editora FGV, 2001, p. 14.

${ }^{43}$ ALENCAR, J. de. Op. cit. p. 914. Grifo meu.

${ }^{44}$ Idem. p. 896. Grifo meu.
} 
ocupado com os assuntos nacionais considerasse a especificidade da forma literária em adequação ao momento histórico em que ela se insere.

José de Alencar, no entanto, não se afasta inteiramente da concepção da literatura como "fato moral". Este aspecto se apresenta, em especial, no momento em que ele ressalta o instinto de missão histórica no qual os autores de sua época devem se empenhar. Alencar salienta a responsabilidade do homem de letras que faz do uso da palavra sua profissão, com sua importante atribuição de representar a voz da nação na posteridade, sem que isso signifique a anulação ou a submissão do mérito propriamente literário. Assim ele escreve na "Oitava carta" e última:

\begin{abstract}
Mas quando o homem em vez de uma ideia, escreve um poema; quando da vida do indivíduo se eleva a vida de um povo, quando ao mesmo tempo historiador do passado e profeta do futuro, ele reconstrói sobre o nada uma geração que desapareceu sobre a face da terra para mostrá-la à posteridade, é preciso que tenha bastante confiança, não só no seu gênio e na sua imaginação, como na palavra que deve fazer surgir esse mundo novo e desconhecido. ${ }^{45}$
\end{abstract}

Acrescentando adiante:

Assim, pois, todo o homem, orador, escritor ou poeta, todo homem que usa da palavra, não como um meio de comunicar as suas ideias, mas como um instrumento de trabalho; todo aquele que fala ou escreve, não por uma necessidade de vida, mas sim para cumprir uma alta missão social; todo aquele que faz da linguagem não um prazer, mas uma bela e nobre profissão, deve estudar e conhecer a fundo a força e os recursos desse elemento de sua atividade. ${ }^{46}$

Diante da missão histórica apresentada por seu tempo, não haveria alternativa ao homem que utilizasse a pena como instrumento de publicização de ideias: a ele caberia desempenhar o papel de portavoz de sua época diante da posteridade, expressão mais bem acabada do que um povo teria a dizer sobre si. Nesse ponto, a obra do literato alcança vida fora do texto e do tempo presente em que circula, acentuando a responsabilidade do homem de letras que utiliza a pena como instrumento de trabalho. Especialmente em um momento como aquele, de formação histórica da nacionalidade brasileira.

Então já não é o poeta que fala; é uma época inteira que exprime pela sua voz as tradições, os fatos e os costumes; é a história, mas a história viva, animada, brilhante como o drama, grande e majestosa como tudo que nos aparece no véu do tempo e da morte. ${ }^{47}$

\title{
Considerações finais
}

O ponto central desenvolvido por José de Alencar na sua crítica ao poema "A Confederação dos Tamoios", de Gonçalves de Magalhães, consiste na defesa de uma forma literária moderna capaz de dar conta da experiência histórica dos homens no tempo, sem que isso representasse um menosprezo a determinadas referências de uma tradição literária ocidental, a qual a literatura brasileira não deveria desprezar. Propõe-se, portanto, uma compreensão da experiência literária que concilie uma forma universal a uma dimensão temporal, ou seja, a compressão de que a historicidade do literário admita perfurações das épocas, conforme as experiências humanas e as diversas possibilidades de devir, sem desprezar o legado

\footnotetext{
45 Idem. p. 891.

46 Idem. p. 890.

47 Idem. p. 891. 
deixado pelas gerações passadas. Por outro lado, ao compreender a tarefa da escrita literária como missão histórica de seu tempo, Alencar requisita do literário uma dimensão que está para além dele, isto é, que ele contribua, à sua maneira, com a tarefa da formação da nacionalidade brasileira, tarefa que associa continuamente política e letras. E nesse ponto, a crítica à "Confederação dos Tamoios" representa muito mais a adesão de Alencar ao programa desenhando por Magalhães e seus companheiros.

Na passagem abaixo, em que enaltece o estilo do romancista escocês Walter Scott, Alencar deixa uma pista sobre qual forma literária estaria em melhor acordo com a cor temporal brasileira:

Estou bem persuadido que se Walter Scott traduzisse esses versos portugueses no seu estilo elegante e correto; se fizesse desse poema um romance, dar-lhe-ia um encanto e um interesse que obrigariam o leitor que folheasse as primeiras páginas do livro a lê-lo com prazer e curiosidade. ${ }^{48}$

Tal ponto é retomado no posfácio da primeira edição de Iracema, de 1865, denominado "Carta ao Dr. Jaguaribe":

\begin{abstract}
Em um desses volveres do espírito à obra começada, lembrou-me de fazer uma experiência em prosa. $O$ verso pela sua dignidade e nobreza não comporta certa flexibilidade de expressão que, entretanto, não vai mal à prosa a mais elevada. $A$ elasticidade da frase permitiria então que se empregassem com mais clareza as imagens indígenas, de modo a não passarem despercebidas. Por outro lado conhecer-se-ia o efeito que havia de ter o verso pelo efeito que tivesse a prosa. ${ }^{49}$
\end{abstract}

As condições históricas da sociedade brasileira e de sua literatura tornariam o romance, por sua "flexibilidade de expressão" e "elasticidade da frase", o gênero literário capaz de dar conta da própria modernidade brasileira.

Daniel Pinha Silva: Doutor em História Social da Cultura pela Pontifícia Universidade Católica do Rio de Janeiro (PUC-Rio). Atualmente é Professor Ajunto da área de História do Brasil da Universidade do Estado do Rio de Janeiro (UERJ).

48 Idem. p. 893.

49 ALENCAR, José de. "Iracema". In: __. Obra Completa. Rio de Janeiro: Editora José Aguilar, 1959, vol. III, p. 307. Grifo meu. 